ECCOMAS

Proceedia
COMPDYN 2021

$8^{\text {th }}$ ECCOMAS Thematic Conference on Computational Methods in Structural Dynamics and Earthquake Engineering

M. Papadrakakis, M. Fragiadakis (eds.) Streamed from Athens, Greece, 28 - 30 June 2021

\title{
SEISMIC VULNERABILITY ANALYSIS OF THE HISTORICAL SS FILIPPO E GIACOMO MASONRY ARCH BRIDGE IN ASCOLI PICENO (ITALY)
}

\author{
G. Leoni ${ }^{1}$, F. Gara ${ }^{2}$, and M. Morici ${ }^{1}$ \\ ${ }^{1}$ University of Camerino, School of Architecture and Design \\ 63100 Ascoli Piceno, Italy \\ e-mail: \{graziano.leoni, michele.morici\}@unicam.it \\ ${ }^{2}$ Università Politecnica delle Marche, Department of Construction, Civil Engineering and Architecture \\ 60131 Ancona, Italy \\ f.gara@univpm.it
}

\begin{abstract}
The bridge was built in 14th century and had undergone very complex vicissitudes related mainly to exceptional floods; it was partially rebuilt twice and other strengthening works were carried out over the time. The bridge, which is almost completely built with travertine blocks, has a total length of $146 \mathrm{~m}$ and follows a slightly curved path. Six arches, the main of which is semi-circular with span of $25 \mathrm{~m}$ and the others are lancet arches with span of about $8 \mathrm{~m}$, support the carriageway that is about $8 \mathrm{~m}$ wide. The piers and abutments are founded on the bedrock and consequently some piers are deeply embedded in the sandy gravel deposit.

A 3D numerical Finite Element Model has been developed integrating data available from the geometric survey and calibrating the mechanical parameters starting from experimental tests. The global seismic vulnerability of the bridge has been evaluated comparing the capacity curves of the bridge obtained by means a static nonlinear pushover analysis with the Italian Standard seismic demand. In addition, local vulnerability verifications of spandrel walls have been carried out by means a linear kinematic analysis.
\end{abstract}

Keywords: Stone Masonry Bridges, Finite Element Models, Vulnerability Analysis, Experimental In-Situ Tests.

ISSN:2623-3347 @ 2021 The Authors. Published by Eccomas Proceedia.

Peer-review under responsibility of the organizing committee of COMPDYN 2021.

doi: $10.7712 / 120121.8722 .18844$ 


\section{INTRODUCTION}

The presence of unreinforced masonry arch bridges in the Italian roads networks is very widespread and given that high seismic risk of some areas, it is very important for the public network authorities to evaluate their capacity.

Evaluation of the capacity of a historical masonry structure is a difficult task because of many uncertainties associated with the knowledge of the structure in its current conditions (original structure and structural changes due to repair enlargement and retrofit works, different construction systems and different materials, structural and material degradation and damages, soil and foundation modifications) and also due to modelling techniques complexity as well as to analysis methods. In this sense, after a deep historical analysis and a complete geometrical and structural survey, sophisticated measurement techniques are necessary to catch the real behaviour of the structure, especially the mechanical properties of the structural materials and the global dynamic behaviour.

Regarding the material survey, both traditional techniques and innovative methods are available but non destructive techniques are generally preferred when dealing with historic and valuable structures. Numerous procedures for the evaluation of the mechanical properties of structural materials have been proposed and the mapping of the building evolution or construction details that can be adopted even in cases where retrofitting interventions have been carried out. The dynamic tests, the subsequent structural identification and the updating of a numerical model of the structure to match the experimental results [1-3] is the most widely diffused approach. The experimental modal parameters evaluated starting from the dynamic tests, can then be used to update refined finite element models able to describe the real behaviour of structures, which can be required for structural verifications and for designing repair and retrofit works [4-6].

Regarding the modelling techniques, in the last decades several procedure was developed aimed to predict the behaviour to arch masonry bridges. The difficulty to describe the interaction between the filling material and the resistant masonry arch requires the use of a complex and effective structural model [7]. Generally methodologies, based on Limit Analysis [8-11] and non linear incremental techniques [12-15], are usually refer to bidimensional arches. Improved bidimensional models, which take into account the arch-fill interaction, were also developed [17-18]. In addition, three-dimensional FEM models [18-20] allow both a complete description of the bridge geometry and detailed constitutive models. Regarding the seismic assessment of masonry arch bridges, only a few studies are available today concern the procedure to evaluation of the safety of the bridge [21].

This paper presents the global seismic vulnerability of the SS. Filippo and Giacomo Bridge over the Tronto river at Ascoli Piceno, in the centre of Italy. The bridge was built in the XIV century and was then subjected to many changes for repair, strengthening, retrofit, and enlargement works. This results in a large complexity of the structural organism, due to interaction between parts of different age which are made of materials with different mechanical properties. Due to these uncertainties and considering the importance of the bridge an accurate analysis of its current conditions was deemed essential to obtain a reliable predictive finite element model to be used for the design of seismic retrofit. First of all a historic study and geometric survey of the bridge were developed. For the material properties in-situ tests, both destructive and non-destructive, were carried out, to evaluate the quality of the travertine block masonry. These information were used to develop a refined 3D finite element model that was tuned based on the experimental modal parameters; in particular, the Young's modulus of some materials initially defined according to standard values suggested by codes, was calibrated to fit the dynamic behaviour obtained experimentally. Starting from the calibrated 
modal, the capacity curves of the bridge obtained by means a static nonlinear pushover analysis are evaluated considering the elastoplastic materials for the bridge and adopting the yield criterion of Mohr-Coulomb. The capacity is compared with the Italian Standard seismic demand, following the well known "N2 method" included in the European codes [22]. In addition, local vulnerability verifications of spandrel walls have been carried out by means a linear kinematic analysis.

\section{2 “SS. FILIPPO AND GIACOMO" BRIDGE}

"SS. Filippo and Giacomo" Bridge rises in the outskirts of Ascoli Piceno town crosses the Tronto River, and is built between two rock escarpments one of which is characterized by an important slope (Figure 1).

It has a total length of $146 \mathrm{~m}$ and maximum height over $20 \mathrm{~m}$, and it is constituted by six arches. The main arch crosses the river during its regular flow and has a semicircular shape with span of about $25 \mathrm{~m}$. The arch barrel has the minimum thickness of $0.90 \mathrm{~m}$ at the crown and increases up to $1.40 \mathrm{~m}$ at the imposts. The other five arches are lancet shaped with span of about $8 \mathrm{~m}$. The depth of the fill at the crowns of arches is variable from about 6.0 to $7.5 \mathrm{~m}$. The aspect of the present "SS. Filippo and Giacomo" Bridge derives from a complex sequence of events occurred over almost six hundred years life (Figure 2).

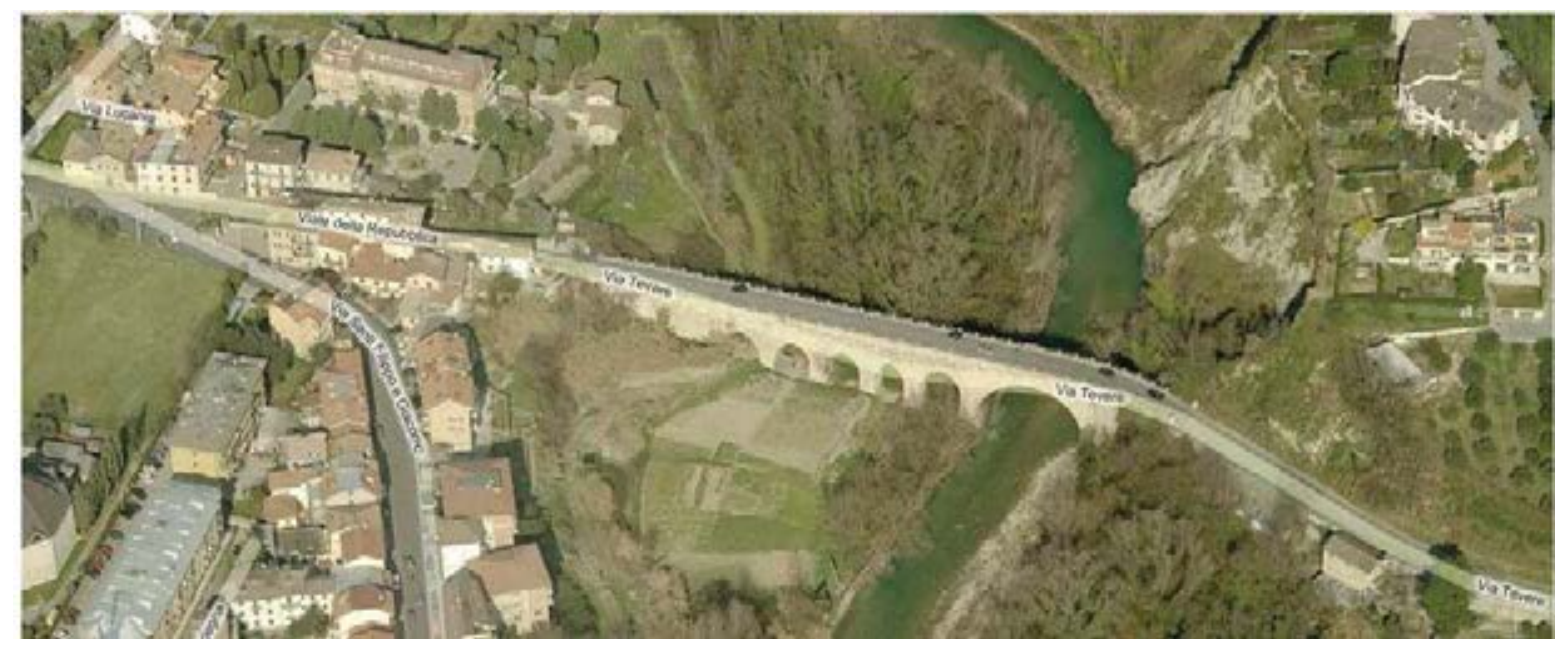

Figure 1: Aerial photogrammetric bridge view.

The former bridge, dating back to the second half of XIV century, was probably constituted by four semicircular arches. It was seriously damaged by a flood occurred in 1453 that produced the collapse of three arches at the right side, the bridge was rebuilding started around 1464, rebuilding the collapsed section with lancet arches reducing spans with respect to the original arches.

A second exceptional flood, occurred in 1528, produced the collapse of the main arch survived to the previous event. This was rebuilt starting from 1545 by means of two parallel barrel-vaults: the vault placed downstream, about $3 \mathrm{~m}$ wide, has remained almost unchanged; the vault placed up-stream, with variable width, underwent an important vertical settlement (of about $0.4 \mathrm{~m}$ ) and was finally rebuilt in 1667 by placing wooden and iron ties aimed at tightening together the two parts. In 1721, a new flood produced the collapse of a not well specified wall (probably a wing wall or a part of the abutment at the left riverbank).

A cutwater was realized to protect the main pier in 1794. The two arches sustained by the main pier were restored between 1835 and 1836. At the end of these works, two barrel-vaults 
were built instead of reinstating the earth fill at the extrados of the main arch in order to facilitate the maintenance of the structure. The two vaults are sustained by the bridge spandrel walls.

Works to reduce the slope of the upper road were carried out between 1849 and 1850: the spandrel walls were raised placing an earth fill in between after having stabilized the system by means of transverse ties placed at two meters from the old top level. At the same time, the ending bend was modified placing side travertine corbels with variable span up to $1 \mathrm{~m}$ in order to widen the carriageway. Such corbels were then connected by brick arches having thickness of $0.30 \mathrm{~m}$. A new order of internal lightening rooms was built over the main arch during this phase; the rooms are spaced as the external pensile arches so that the stone corbels are placed in the walls separating the rooms. Each room is vaulted orthogonally to the lower level previously realized.

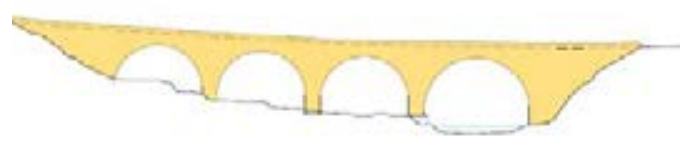

$1373-1418$

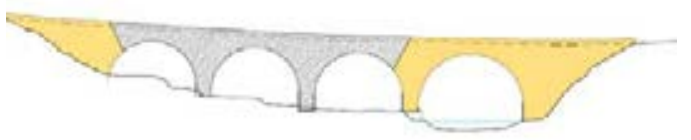

1453

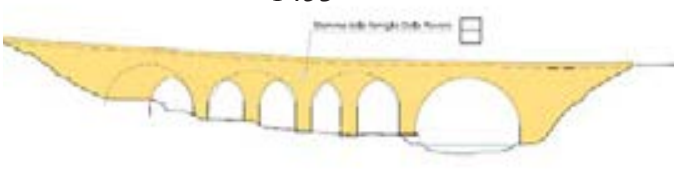

$1464-1477$

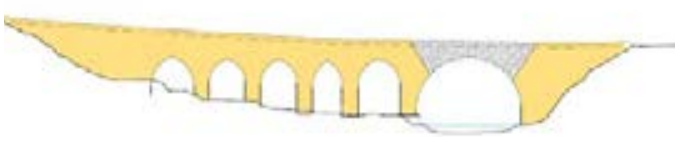

1528
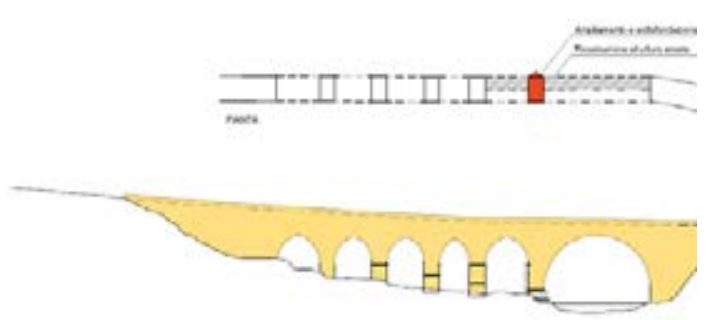

$1832-1839$

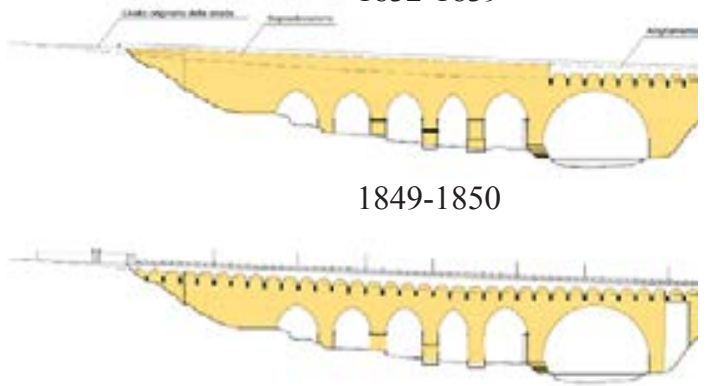

1932

Figure 2: Synopsys of historical vicissitudes.

\subsection{Current geometrical configuration and crack pattern}

The bridge rises between two rock escarpments pro-duced by erosion of Tronto River (Figure 3). The left escarpment has a rather high slope $\left(52^{\circ}\right)$ whereas the right one is less sloping $\left(31^{\circ}\right)$. The gorge is charac-terized by a sandy gravel deposit on the right riverbank, with variable thickness up to $10 \mathrm{~m}$, whereas the sandstone bedrock is outcropping at the left riverbank. Investigations carried out in corre-spondence of piers P1, P2 and P3 demonstrated that foundations are placed at the sandstone bedrock which is horizontal; despite other specific analyses were not carried out for the other piers (P4 and P5) there is no evidence (vertical settlements) that these are founded over the deposit; the sandy gravel deposit is thus placed around the pier but not under the foundation layer.

The bridge exhibits a crack pattern characterized by cracks with vertical orientation located at the mortar joints. Such cracks are located at the base section of piers P1, P2 and P3 (Figure 4) and may be attributed to stress states due to vertical loads associated to the settling of masonry that is widely characterized by deteriorated mortar joints. 

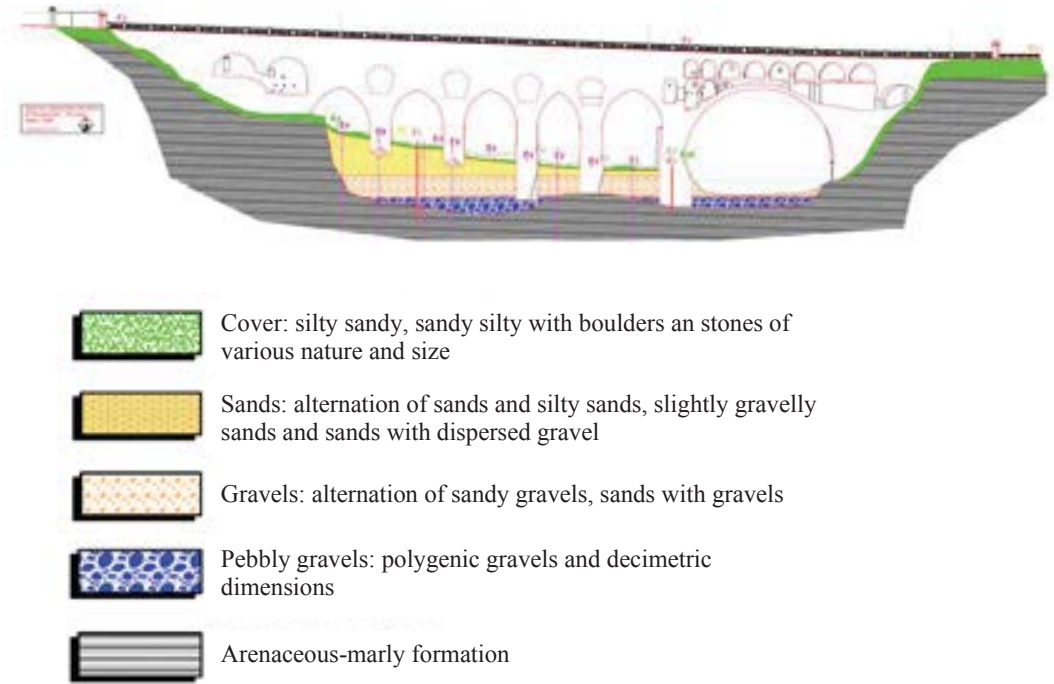

Figure 3: Geological configuration and foundation level.

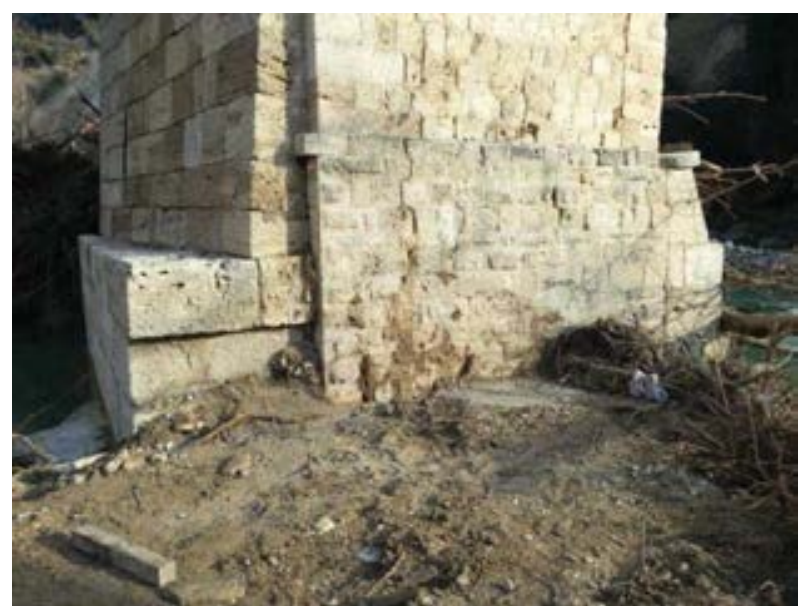

(a)

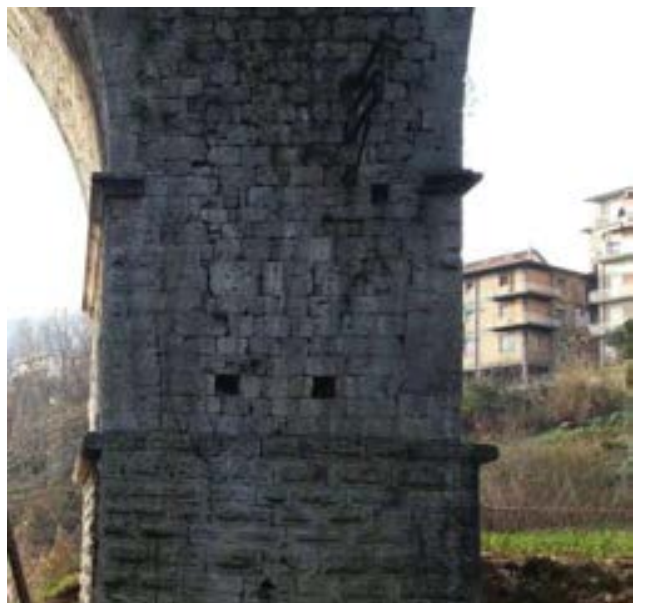

(b)

Figure 4. (a) crack pattern at the bottom of pier P1; (b) cracks of pier P3.

\subsection{Geometrical and material survey}

The range-based survey used to acquire geometrical/metric data was made by means of a 3D-TOF laser scanner technique. Both the external geometry and the geometry of the various internal vaulted rooms over the main arch, at the pier top and at the abutments, were surveyed. Wooden and steel ties, placed to avoid the spandrel wall overturning toward outside were also surveyed in the accessible zones. The acquired data-set was then processed to obtain a refined $3 \mathrm{D}$ geometrical model that was later used to generate a structural model with very precise geometry and rigorous mass distributions. Such a kind of survey revealed to be extremely useful in the case under consideration characterized by a very complex geometry.

\section{TESTS ON MATERIALS}

Materials were characterized by onsite tests namely two tests with single flat jacks and one test with double flat jacks. Three compression tests on travertine speci-mens sampled by means of masonry coring were al-so executed. Sampling and test locations are report-ed in Figure 5. 
Masonry coring permitted to observe that the pier structure is characterized by an external curtain, having variable thickness and realized with Ascoli Piceno travertine squared blocks, and an important inter-nal, rather irregular, rubble stone infill characterized by the presence of water in the lower parts.

Compressive tests carried out on the three specimens gave scattered results with minimum strength $16.9 \mathrm{~N} / \mathrm{mm}^{2}$. The double flat jack test carried out at the base of pier P2 provided a linear behavior in the stress range investigated (up to about $4 \mathrm{~N} / \mathrm{mm}^{2}$ ), characterized by Young's modulus of about $6600 \mathrm{~N} / \mathrm{mm}^{2}$. Single flat jack tests carried out at the base of piers $\mathrm{P} 1$ and P2 permitted the estimation of the stress state in the external masonry curtains. For pier P1 the stress state obtained is higher than for pier P2, as expected; in particular the normal vertical stress in $\mathrm{P} 1$ is about $1.3 \mathrm{~N} / \mathrm{mm}^{2}$ while for pier $\mathrm{P} 2$ it is about $0.5 \mathrm{~N} / \mathrm{mm}^{2}$.

For what concerns the masonry of the interior vaulted rooms, tests were not carried out because from the inspection and the laser scanner survey it was evident that it is a good brick masonry. Never-theless, it is worth noticing that such components are not expected to give a significant contribution to the overall behavior of the structure excepting for the mass.

The two kinds of masonry constituting the bridge structure can be classified according to catalogs re-ported in design guidelines and standards. Italian Standards [23-24] provide the mechanical characteristic reported in Table 1.

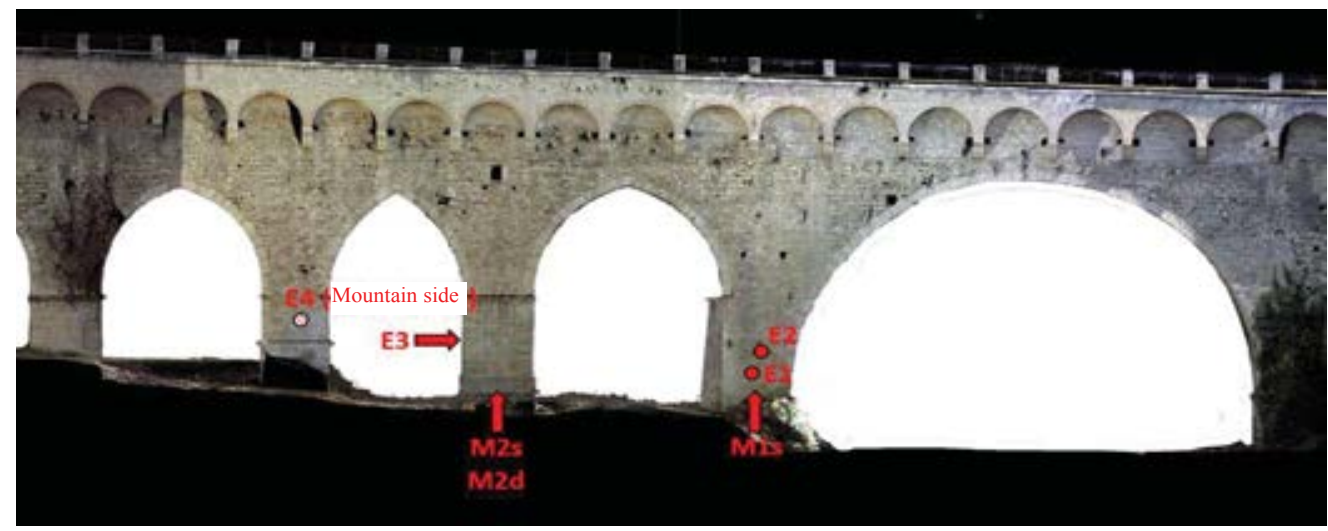

Figure 5. Location of sampling and onsite tests

\begin{tabular}{llll}
\hline Masonry & $\begin{array}{l}\mathrm{E} \\
\left(\mathrm{N} / \mathrm{mm}^{2}\right)\end{array}$ & $\begin{array}{l}\mathrm{G} \\
\left(\mathrm{N} / \mathrm{mm}^{2}\right)\end{array}$ & $\begin{array}{l}\mathrm{W} \\
\left(\mathrm{kN} / \mathrm{m}^{3}\right)\end{array}$ \\
\hline Curtains of stone squared & 1680 & 546 & 22 \\
blocks with poor core & 2240 & 658 & \\
\multirow{2}{*}{ Bricks with lime mortar } & 1200 & 400 & \multirow{2}{*}{18} \\
& 1800 & 600 & \\
\hline
\end{tabular}

Table 1. Mechanical characteristics deriving from on-site tests

In addition the modal parameters of the bridge, i.e. natural frequencies, damping ratios and mode shapes, are experimentally estimated by means of operational modal analysis starting from the accelerations of the deck recorded during ambient vibration measurements which are mainly due to traffic, wind and microtremors. Results obtained from this test was adopted to calibrate the elastic value of the materials used in the model. 


\section{STRUCTURAL MODEL OF THE BRIDGE}

The 3D Finite Element Model (FEM) intended for the structural analyses is developed in Straus7 [25] starting from the data available from the laser scanner survey. In order to avoid excessive refinement of the mesh due to details that do not actually affect the overall behavior of the bridge, the geometry was simplified. Part of the soil portion in the riverbed at the base of internal piers was included in the model, to takes into account the particular geological formation and capture the soil-pier interaction phenomena. In addition, all internal rooms and the earth fill was considered in the model to capture the real stiffness and mass distribution in the structure (Figure 6a).

The finite element model is obtained with a mesh of 4-node tetrahedral elements with linear interpolation shape functions (Tetra4). The mesh is generated by importing a closed polysurface constructed by approximating the geometry obtained with the laser scanner survey. Based on previous consideration, the geometry was simplified imposing the maximum length of the element edge of $1.0 \mathrm{~m}$ for the bridge structure, whereas it was increased up to $4.5 \mathrm{~m}$ for the elements belonging the soil deposit (Figure 6b). Fixity restraint are placed at the deposit base and at the structure sections interacting with the sand stone formation. All the materials, including earth fills and the soil deposit, are considered to be linear elastic and isotropic.

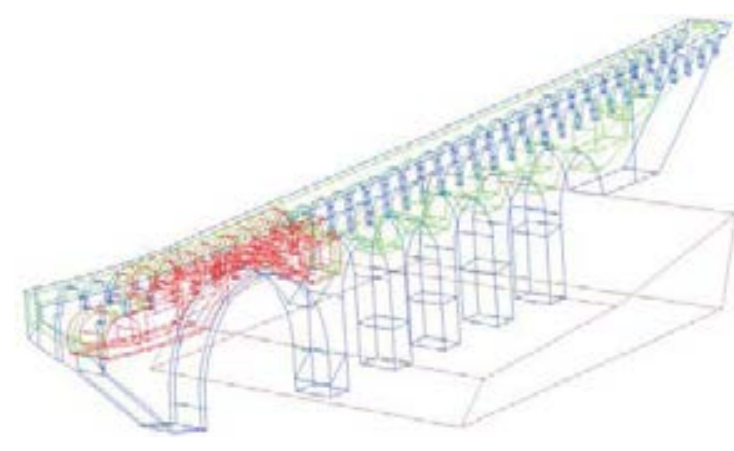

(a)

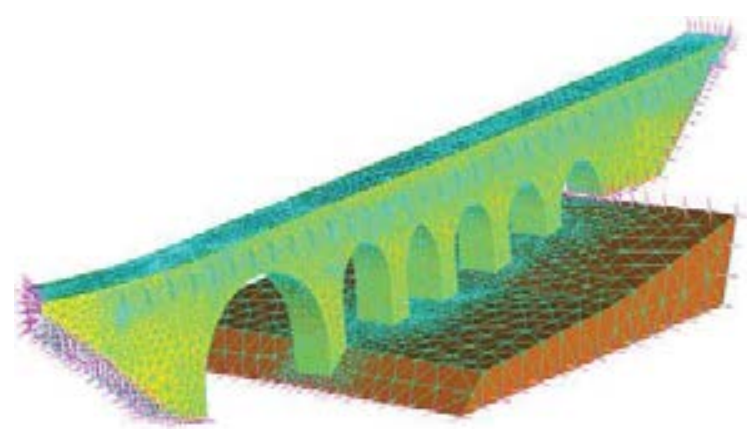

(b)

Figure 6. (a) Geometrical model; (b) Finite element model.

The mechanical parameters of the finite element model was assumed elastic-plastic, considering the yield criterion of Mohr-Coulomb. Regarding the initial condition, elastic parameters are calibrated by fitting the experimental modal parameters with numerical ones relevant to the finite element model previously discussed. Regarding the soil parameters, are derived from geotechnical in situ test, while the infill materials are hypothesized based on construction techniques.

\begin{tabular}{cccccc}
\hline Materials & $\begin{array}{c}\mathrm{E} \\
\left(\mathrm{N} / \mathrm{mm}^{2}\right)\end{array}$ & $\begin{array}{c}\mathrm{G} \\
\left(\mathrm{N} / \mathrm{mm}^{2}\right)\end{array}$ & $\begin{array}{c}\mathrm{W} \\
\left(\mathrm{kN} / \mathrm{m}^{3}\right)\end{array}$ & $\begin{array}{c}\mathrm{c} \\
\left(\mathrm{N} / \mathrm{mm}^{2}\right)\end{array}$ & $\begin{array}{c}\phi \\
{\left[{ }^{\circ}\right]}\end{array}$ \\
\hline Travertine masonry & 7000 & 2414 & 22 & 0.256 & 76.0 \\
Brick masonry & 1282 & 427 & 18 & 0.214 & 72.0 \\
Earth infill material & 666 & 238 & 18 & 0.010 & 42.5 \\
Base soil deposit & 666 & 243 & 19 & 0.010 & 32.0
\end{tabular}

Table 4. Mechanical parameters considered in the analyses 


\section{SEISMIC DEMAND}

The area where the bridge is located falls within an area of medium seismic hazard. According to the seismic Italian Standard Code [23-24], in Figure 7a is reported the seismic hazard curve at the arch bridge site in terms of Peak Ground Acceleration (PGA) $a_{g}$, varying the return period $T_{R}$. Considering the $T_{R}$ equal to 475 years, the PGA assume the value of $\mathrm{a}_{\mathrm{g}}=0.178 \mathrm{~g}$. For the site effect, a subsoil category B been assumed for the subsoil condition and category $\mathrm{T}_{2}$ regarding the topographic condition. In Figure $7 \mathrm{~b}$ is reported the corresponding elastic response spectrum considering for the site considered in the following analyses.

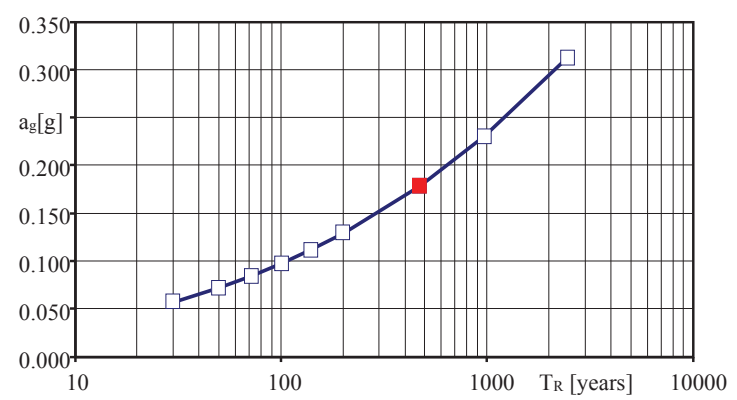

(a)

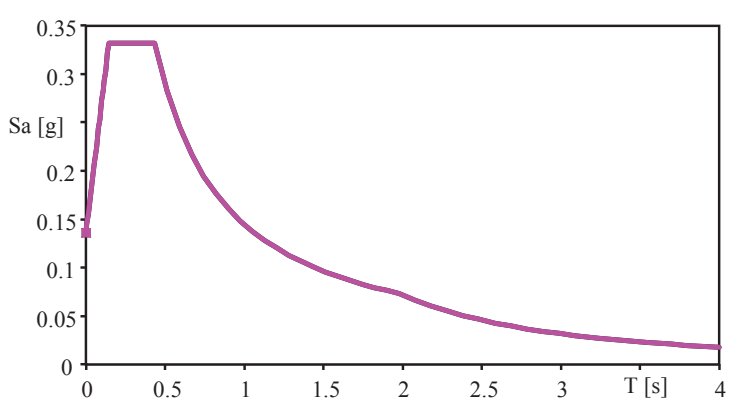

(b)

Figure 7. (a) Seismic hazard curve at the arch bridge site; (b) Elastic response spectrum

\section{EVALUATIO OF THE SEISMIC CAPACITY}

\subsection{Non linear static analysis}

The assessment of the capacity of the masonry arch bridge is evaluated following the methods included in the European codes, based on the N2 method [26], that combines the non-linear static analysis of the multi-degree of freedom model with the response spectrum analysis of an equivalent single degree of freedom system.

Capacity analyses is performed by applying two different distributions of the lateral loads: a "modal" pattern (which will be hereafter referred to as "mode 1") corresponding to a distribution of the acceleration proportional to the $1^{\text {st }}$ modal shape; a "uniform" pattern, based on lateral forces proportional to mass regardless of elevation (uniform response acceleration).

During the loading process, the transversal displacement of the control point located in the position of maximum modal deformation is monitored, in order to trace the pushover curve in terms of the equivalent lateral load. Afterwards, the pushover curve is transformed into a simplified bilinear force-displacement relationship for an equivalent inelastic SDOF system, based on the equivalence of energy between two systems. Results relevant to SDOF system is reported in the plane Acceleration-Displacement Response Spectra (ADRS) and evaluating the inelastic spectrum for the return period $T_{R}^{*}$ consistent with the capacity of the equivalent SDOF (condition of equal displacement).

Figures $10 \mathrm{a}-\mathrm{b}$ and Figures $11 \mathrm{a}-\mathrm{b}$ reports the stresses of the component $\mathrm{ZZ}$ and XX respectively considering the distribution of lateral loads proportional to $1^{\text {st }}$ modal shape at the end of analysis in positive/negative $\mathrm{Y}$ direction.

Figures $12 \mathrm{a}-\mathrm{b}$ and Figures 13a-b reports the stresses of the component $\mathrm{ZZ}$ and $\mathrm{XX}$ respectively considering the distribution of lateral loads proportional to mass regardless of elevation at the end of analysis in positive/negative $\mathrm{Y}$ direction.

Figures 10c-Figures 13c shows the equivalent SDOF evaluated starting from the non-linear pushover analyses, and Figures 10d-Figures $13 \mathrm{~d}$ shows the verifications in verification in ADRS plane. 
Finally, Table 5 summarise the Index Risk $\left(I_{R}\right)$ evaluated by the expression [27]:

$$
\mathrm{I}_{\mathrm{R}}=\frac{\mathrm{T}_{\mathrm{R}}}{\mathrm{T}_{\mathrm{R}}^{*}}
$$
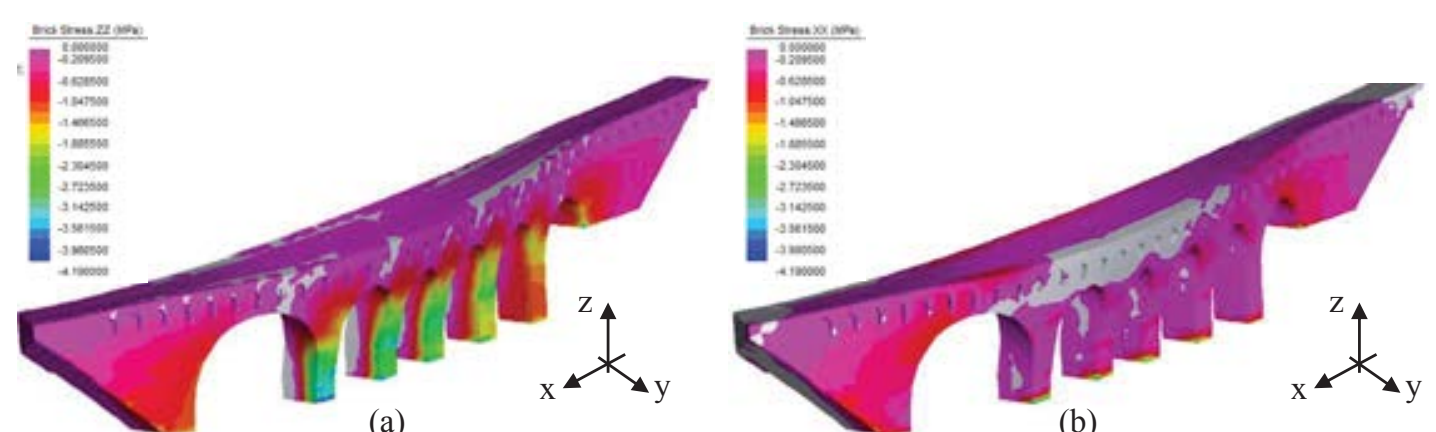

(a)

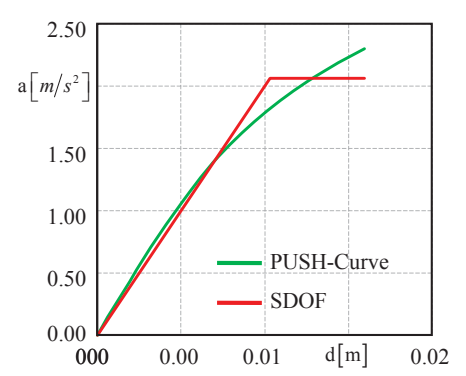

(c)

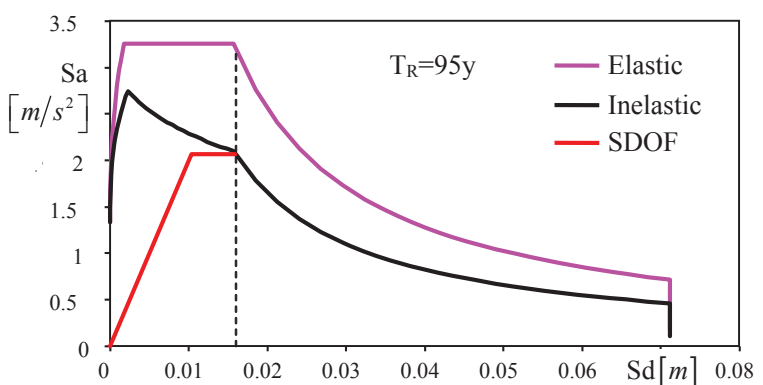

(d)

Figure 8. Pushover analysis considering lateral load proportional to $1^{\text {st }}$ modal shape (Y+ direction): (a) ZZ stresses components at the maximum displacements; (b) XX stresses components at the maximum displacements; (c) bilinear equivalent SDOF; (d) verification in ADRS plane.
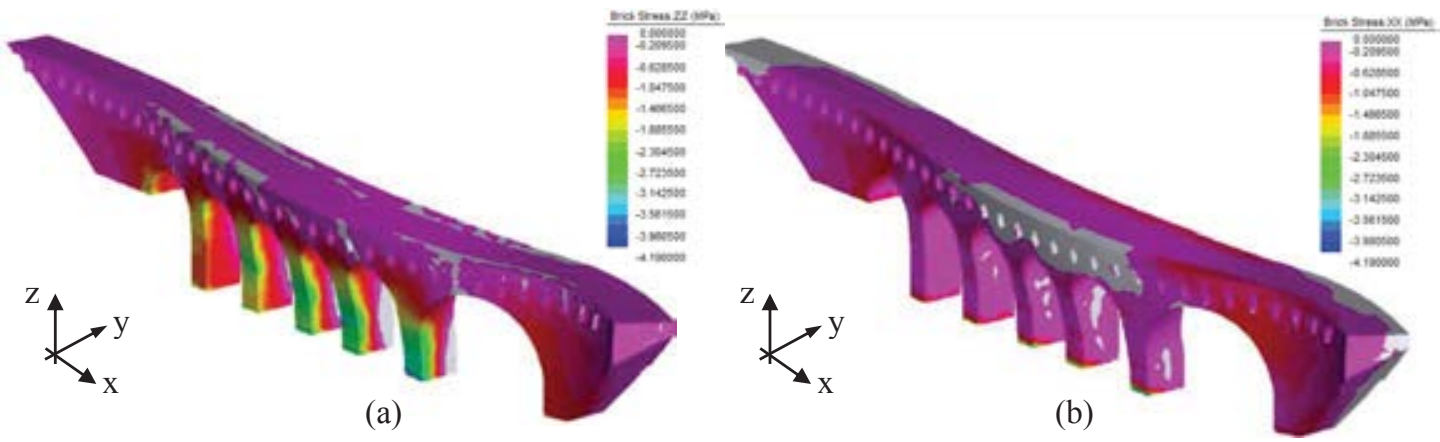

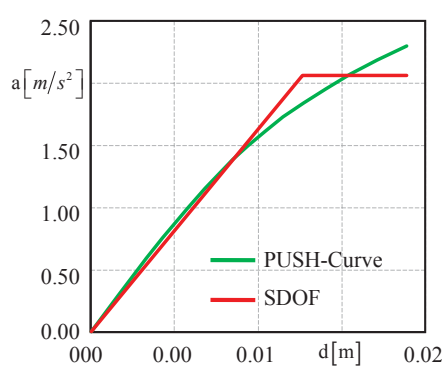

(c)

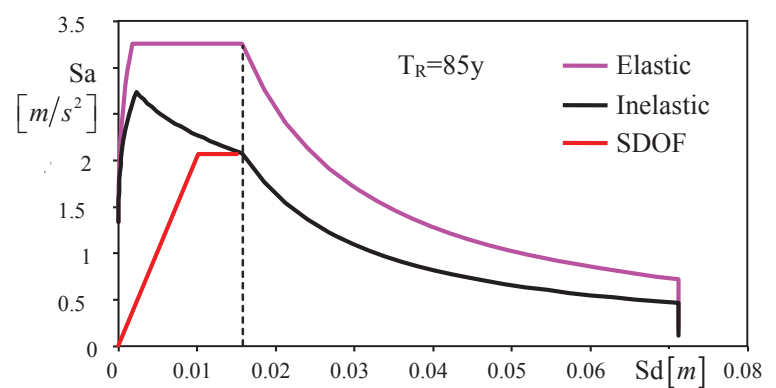

(d)

Figure 9. Pushover analysis considering lateral load proportional to $1^{\text {st }}$ modal shape (Y- direction): (a) ZZ stresses components at the maximum displacements; (b) XX stresses components at the maximum displacements; (c) bilinear equivalent SDOF; (d) verification in ADRS plane. 

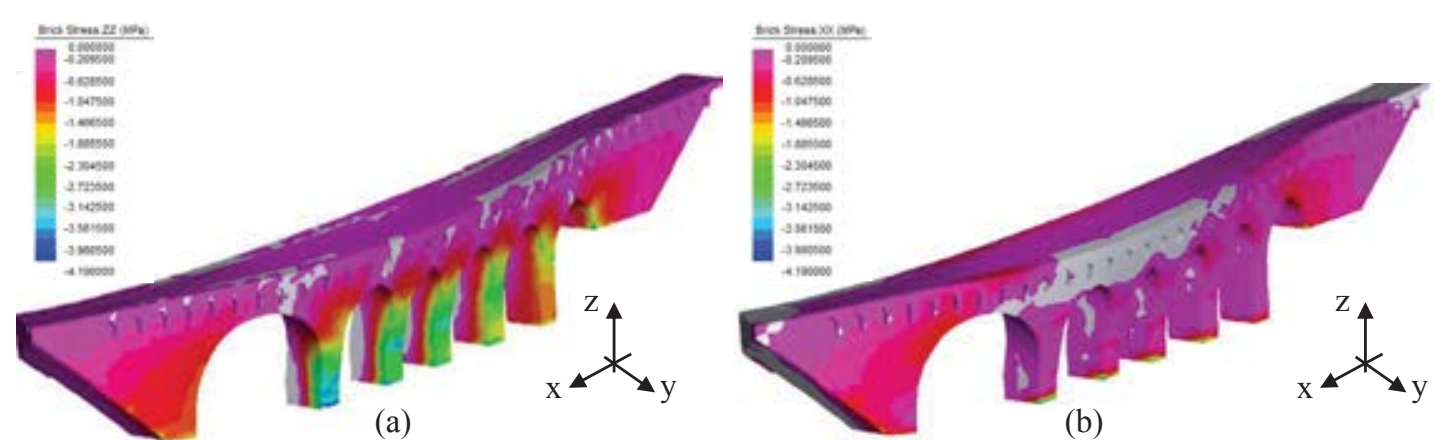

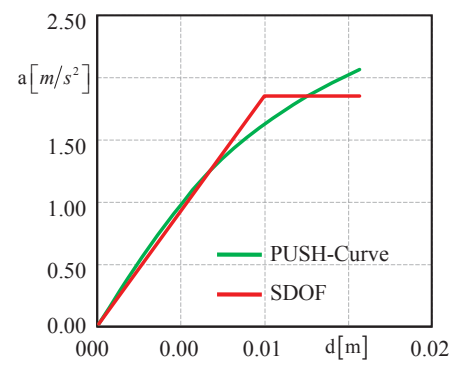

(c)

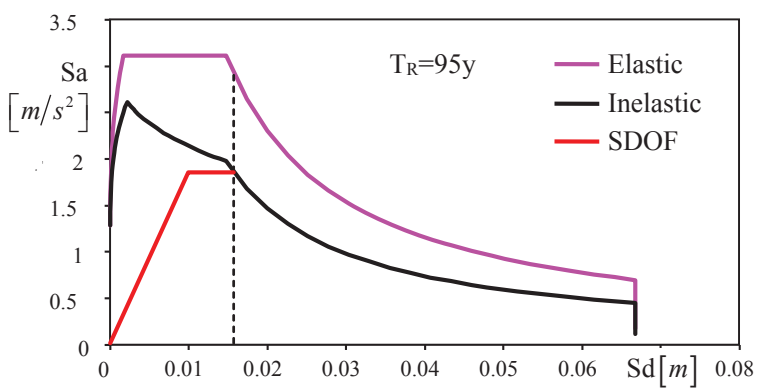

(d)

Figure 10. Pushover analysis considering lateral load proportional to masses distribution (Y+ direction): (a) ZZ stresses components at the maximum displacements; (b) XX stresses components at the maximum displacements; (c) bilinear equivalent SDOF; (d) verification in ADRS plane.
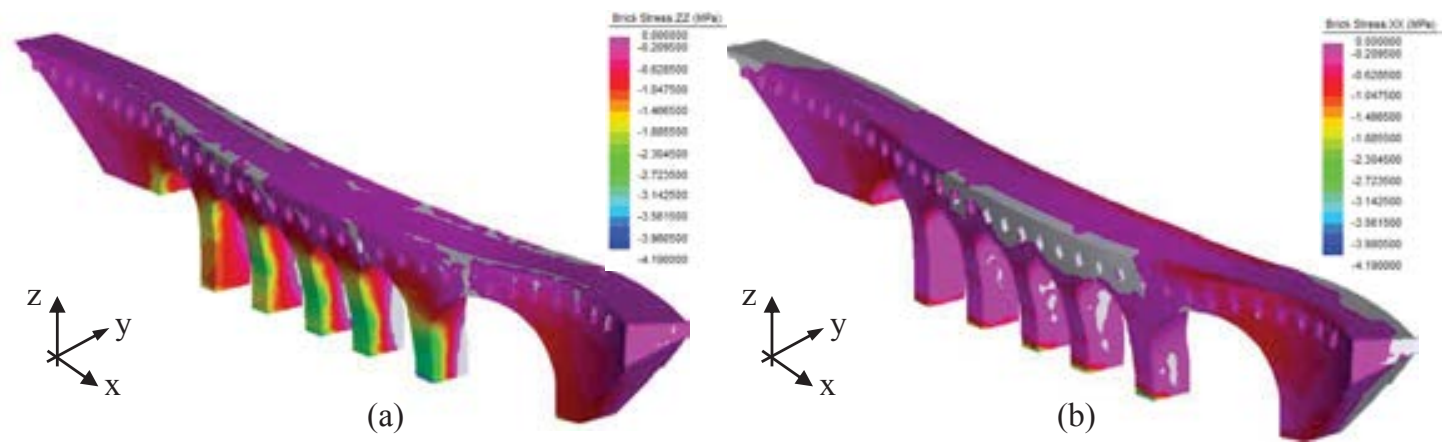

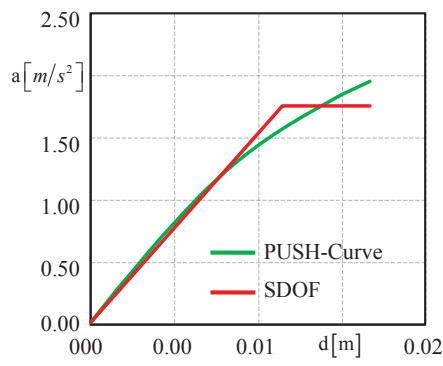

(c)

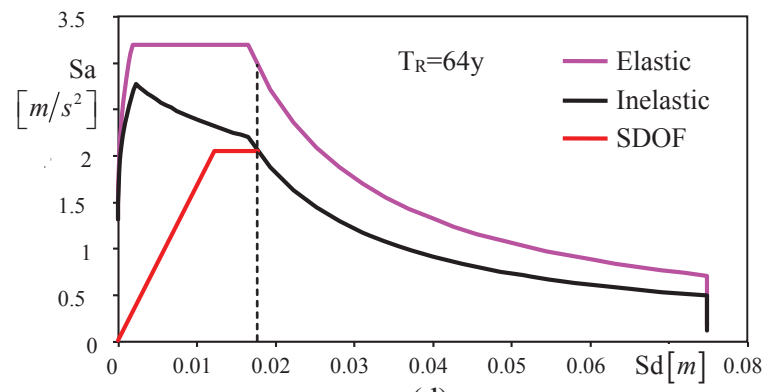

(d)

Figure 11. Pushover analysis considering lateral load proportional to masses distribution (Y- direction): (a) ZZ stresses components at the maximum displacements; (b) XX stresses components at the maximum displacements; (c) bilinear equivalent SDOF; (d) verification in ADRS plane. 


\begin{tabular}{|c|c|}
\hline Analysis & $\mathrm{I}_{\mathrm{R}}$ \\
\hline MODE Y+ & 0.20 \\
\hline MODE Y- & 0.20 \\
\hline MASS Y+ & 0.18 \\
\hline MASS Y- & 0.13 \\
\hline
\end{tabular}

Table 3. Index Risk

\subsection{Local analysis}

The main local vulnerabilities consist in the overturning of the bridge tympanum characterized by the presence of earth filling, in the portion of the bridge above the secondary arches. Assuming the inefficiency of a head connection of the bridge tympanum, the possibility of overturning of the single wall or single hanging arch is expected; it is assumed that the tie added on the occasion of the raising of the bridge are efficient and that therefore the overturning takes place at the tax rate of the arches.

The assessment of local vulnerability is conducted by means of a linear kinematic analysis with reference to the bridge segment between the axes of two consecutive arches placed in correspondence with the third arch (Figure 14a).

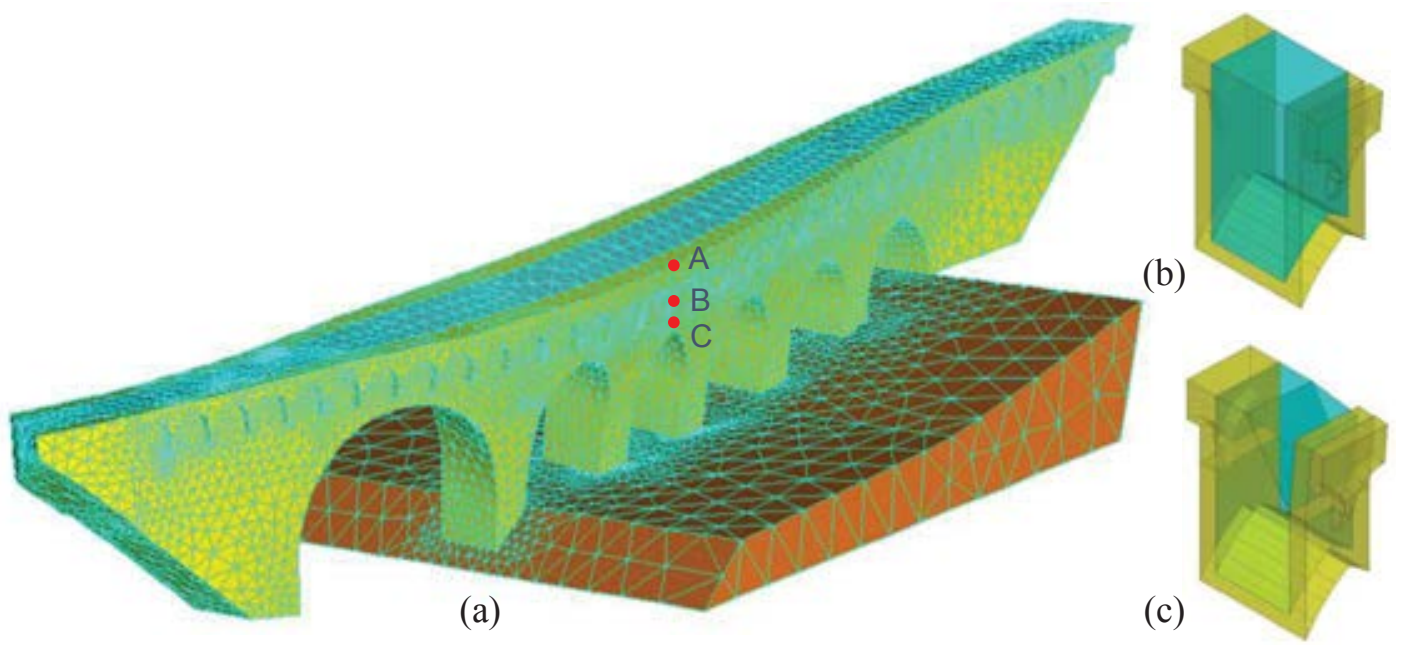

Figure 12. Comparison between experimental and theoretical vibration modes

Figure $14 \mathrm{~b}$ reported the mechanism single hanging arch, while Figure $14 \mathrm{c}$ reported the mechanism relevant to the formation of an active thrust wedge of the infilling material. Regarding the first mechanism the risk index assumed the value $I_{R}=0.08$, while for the second mechanism $I_{R}=0.09$. In both evaluations, the seismic demand is evaluated considering the seismic action corresponding the first period of vibration and behaviour factor equal 2 .

\section{CONCLUSIONS}

The assessment of the seismic vulnerability of a historical masonry bridge, characterized by an unusual geometry deriving by very complex historical vicissitudes, has been presented. The capacity is compared with the with the Italian Standard seismic demand, following the well-known "N2 method"; furthermore, local vulnerability verifications of spandrel walls have been carried out by means a linear kinematic analysis. 
The bridge rises in a gorge and is founded on a sand-stone deposit that is outcropping at the abutments. The bridge is constituted by six different arches whose piers are founded on the sand-stone formation and are embedded for significant sections (up to $10 \mathrm{~m}$ ) into the fluvial deposit constituted by sandy-gravel soil.

A laser scanner survey was crucial to obtain a model encompassing all main features of the real structure such as the inner lightening rooms, with very irregular geometry, as well as the pensile arches constructed to enlarge the carriageway.

The onsite tests permitted to evaluate the main mechanical characteristics of the materials and to estimate the stress state in critical sections of the piers.

The operational modal analysis, used to detect the dynamic behavior of the bridge, was decisive for tuning a finite element model capable of predicting the overall behavior of the bridge, and adopted to evaluate the seismic capacity of the arch bridge.

\section{REFERENCES}

[1] C. Gentile, A. Saisi. Operational modal testing of historic structures at different levels of excitation. Constr Build Mater 48:1273-1285, 2013.

[2] C. Costa, D. Ribeiro, P. Jorge, R. Silva, A. Arêde, R. Calçada. Calibration of the numerical model of a stone masonry railway bridge based on experimentally identified modal parameters. Engineering Structures 123, 354-371, 2016.

[3] S. Gonen, S. Soyoz. Dynamic Identification of Masonry Arch Bridges Using Multiple Methodologies. In: Epp D.S. (eds) Special Topics in Structural Dynamics \& Experimental Techniques, Volume 5. Conference Proceedings of the Society for Experimental Mechanics Series. Springer, Cham., 2021.

[4] A. De Sortis, E. Antonacci, F. Vestroni. Dynamic identification of a masonry building using forced vibration tests. Eng Struct, 27(2): 155-165, 2005.

[5] H. Ahmadian, G.M. Gladwell, F. Ismail. Finite element model identification using modal data. J Sound Vib, 172(5): 657-669, 1994.

[6] J.E. Mottershead, M.I. Friswell. Model updating in structural dynamics: a survey. $J$ Sound Vib, 167(2): 347-375, 1993.

[7] B. Conde, L. Díaz-Vilariño, S. Lagüela, P. Arias. Structural analysis of Monforte de Lemos masonry arch bridge considering the influence of the geometry of the arches and fill material on the collapse load estimation. Construction and Building Materials 120, 630-642, 2016.

[8] J. Heyman. The masonry arch. Chichester: Ellis Horwood; 1982.

[9] M. Gilbert, C. Melbourne. Rigid-block analysis to masonry arches. Structural Engineering; 72: 356-361, 1994.

[10] TG. Hughes, MJ. Blackler. A review of the UK masonry assessment methods. Proceedings of the Institution of Civil Engineers, 110: 373-382, 1995.

[11] Boothby T. Collapse modes of masonry arch bridges. Journal of the British Masonry Society. 9 (2): 62-69, 1995. 
[12] C. Molins, P. Roca. Capacity of masonry arches and spatial frames. J Struct Eng, 124: 653-663, 1988.

[13] A. Brencich, U. De Francesco. Assessment of multi-span masonry Arch bridges. Part I: a simplified approach, Part II: examples and applications. J Bridge Eng ASCE, 9 (November): 582-598, 2004.

[14] A. Audenaert, P. Fanning, L. Sobczak, H. Peremans. 2-D analysis of arch bridges using an elasto-plastic material model. Engineering Structure; 30: 845-855, 2008.

[15] A. Thavalingam, N. Bicanic, J.I. Robinson, D.A. Ponniah. Computational framework for discontinuous modelling of masonry arch bridges. Computers and structures, 79: 1821-1830, 2001.

[16] A. Cavicchi, L. Gambarotta. Collapse analysis of masonry bridges taking into account arch-fill interaction. Engineering Structures, 27: 605-615, 2005.

[17] A. Cavicchi, L. Gambarotta. Lower bound limit analysis of masonry bridges including arch-fill interaction. Engineering Structures, 29: 3002-3014, 2007.

[18] M.E. Stavroulaki, B. Riveiro, G.A. Drosopoulos, M. Solla, P. Koutsianitis, G.E. Stavroulakis. Modelling and strength evaluation of masonry bridges using terrestrial photogrammetry and finite elements. Advances in Engineering Software 101, 136-148, 2016. https://doi.org/10.1016/j.advengsoft.2015.12.007

[19] P.J., Fanning, T.E. Boothby. Three-dimensional modelling and full-scale testing of stone arch bridges. Journal of Computers and Structures 2001; 79 (29-30):2645-2662.

[20] F. Scozzese, L. Ragni, E. Tubaldi, F. Gara. Modal properties variation and collapse assessment of masonry arch bridges under scour action. Engineering Structures 199, 15 November 2019,109665, 2019.

[21] S. Gönen, S. Soyöz. Seismic analysis of a masonry arch bridge using multiple methodologies. Engineering Structures 226, 1 January 2021, 111354, 2021.

[22] Eurocode 8: Design of structures for earthquake resistance- part 1: General rules, seismic actions and rules for buildings.

[23] Norme tecniche per le costruzioni. D.M. Ministero Infrastrutture e Trasporti 2018, Supplemento ordinario alla "Gazzetta Ufficiale n. 42 del 20 febbraio 2018 - Serie generale (In italian), 2018

[24] Istruzioni per l'applicazione delle Nuove norme tecniche per le costruzioni di cui al decreto ministeriale 14 gennaio 2018. Ministero delle Infrastrutture e dei Trasporti e Consiglio Superiore dei Lavori Pubblici, Circolare 21 gennaio 2019, n. 7. Gazzetta Ufficiale n. 35 del 11 febbraio 2019 - supplemento ordinario n. 5 (in Italian), 2019.

[25] Straus7, G+D Computing Pty Limited, http://www.straus7.com

[26] P. Fajfar, A nonlinear analysis method for performance-based seismic design, Earthquake Spectra 16 (3) 573-592), 2000.

[27] Valutazione e riduzione del rischio sismico del patrimonio culturale con riferimento alle NTC 14 gennaio 2008. DPCM 9 febbraio 2011, G.U.R.I., Roma, Italy (in Italian), 2011 . 